\title{
ANALISA PERBEDAAN INFORMASI DIAGNOSTIK CT SCAN KEPALA PADA KASUS STROKE ISKEMIK DENGAN PILIHAN KOMBINASI SLICE THICKNESS DAN INTERVAL RECONSTRUCTION
}

\author{
Mami Dwi Yan ${ }^{1)}$, Jeffri Ardiyanto ${ }^{2)}$, Nanang Sulaksono ${ }^{3)}$ \\ 1),2),3) Poltekkes Kemenkes Semarang \\ e-mail : mamidwiyanradiologi@gmail.com
}

\begin{abstract}
Background: Stroke is a diseas that has a high mortality rate as the third most common disease that causes death in the world. To diagnose the location and type stroke, a neuro imaging examination is need, which is by examining the CT Scan of the head. The purpose of this study was to determine differences in diagnostic information on CT scan of the head in cases of ischemic stroke with a choice combination of $3 \mathrm{~mm}$ slice thickness with $1.5 \mathrm{~mm}$ interval reconstruction and $2 \mathrm{~mm}$ slice thickness with $1 \mathrm{~mm}$ interval reconstruction, and to find out which combination is the most optimal in producing diagnostic information in cases of ischemic stroke.

Methods: This type of research is quantitative research with experimental approach. The study was conducted at Telogorejo Hospital Semarang. The sampel in this study were 10 patients with expertise results of ischemic stroke. The resultan data was 10 head scan radiographs with ischemic stroke and each radiograph is reformatted with combination of $3 \mathrm{~mm}$ slice thickness with 1.5 interval reconstruction and $2 \mathrm{~mm}$ slice thickness with $1 \mathrm{~mm}$ interval reconstruction. Assesment of diagnostic information data was done by 3 respondents. before data analysis, first kappa test was done to three respondents and then tested wilcoxon.

Result :The result of this research is the difference of diagnostic information between combination of $3 \mathrm{~mm}$ slice thickness with $1.5 \mathrm{~mm}$ interval reconstruction and $2 \mathrm{~mm}$ slice thickness with $1 \mathrm{~mm}$ interval reconstruction. A combination of $2 \mathrm{~mm}$ slice thickness with $1 \mathrm{~mm}$ interval reconstruction with mean rank 21.00 is the most optimal combination for head scan with ischemic stroke cases.
\end{abstract}

Keyword: CT scan, slice thickness, interval reconstruction, ischemic stroke

\section{Pendahuluan}

Stroke merupakan suatu tanda klinis yang berkembang cepat akibat gangguan fokal (atau global) dengan gejala-gejala yang berlangsung selama 24 jam atau lebih dan dapat menyebabkan kematian tanpa adanya penyebab lain yang jelas selain vaskular (KSSNP, 1999). Stroke iskemik atau serebral infark merupakan yang paling sering, yaitu 70 - 80\% dari semua kejadian stroke. CT Scan merupakan salah satu modalitas penunjang pada pemeriksaan kepala yang mampu memberikan informasi diagnostik pada kasus stroke.

Pada saat kasus, di area otak terkadang tidak menunjukkan abnormalitas saat beberapa jam awal serangan stroke dikarenakan region yang terlalu kecil atau karena adanya bagian dari otak (brainstem atau cerebellum) yang tidak menunjukkan gambaran yang jelas. Baert (2009) merekomendasikan penggunaan slice thickness dengan ukuran $3 \mathrm{~mm}$ untuk memperlihatkan gambaran infark secara jelas. Sementara, Hosten dan Liebeg (2002) merekomendasikan slice thickness dengan ukuran $2 \mathrm{~mm}$ untuk memperlihatkan secara optimal gambaran infark. Untuk nilai interval reconstruction, Wicaksono (2017) menyarankan bahwa nilai interval reconstruction yang optimal adalah $50 \%$ dari nilai slice thickness yang digunakan. Baert (2011) juga merekomendasikan untuk menggunakan nilai interval reconstruction yang lebih kecil dari ukuran slice thickness (50\% dari ukuran slice thickness) untuk memperlihatkan lesi yang kecil.

Pada pemeriksaan CT Scan kepala, seorang radiografer harus dapat menentukan slice thickness dan nilai interval reconstruction yang tepat untuk menghasilkan informasi diagnostik yang optimal. Atas dasar pentingnya penggunaan slice thickness dan interval reconstruction, maka perlu dilakukan penelitian yang bertujuan untuk mengetahui perbedaan informasi diagnostik pada CT Scan kepala dengan kasus stroke iskemik antara pilihan kombinasi slice thickness $3 \mathrm{~mm}$ dengan interval reconstruction $1.5 \mathrm{~mm}$ dan slice thickness $2 \mathrm{~mm}$ dengan interval reconstruction $1 \mathrm{~mm}$.

\section{Metode}

Jenis penelitian ini adalah penelitian kuantitatif dengan pendekatan eksperimental. Pengambilan data dilakukan pada bulan April sampai Mei 2018. Populasi dan sample penelitian adalah citra CT Scan kepala dengan potongan axial pada kasus stroke iskemik dengan sampel yang terdiri dari 10 pasien dan setiap radiograf direformat dengan pilihan kombinasi slice thickness $3 \mathrm{~mm}$ dengan interval reconstruction $1.5 \mathrm{~mm}$ dan slice thickness $2 \mathrm{~mm}$ dengan interval reconstruction $1 \mathrm{~mm}$, sehingga didapatlkan 20 citra. Pesawat yang digunakan CT Scan Ge Light Speed VCT 64 slice. Metode pengambilan data dengan kuesioner informasi diagnostik terhadap 3 orang dokter spesialis radiologi.

Data dari hasil responden berupa data ordinal yang akan diolah dan dianalisa dengan aplikasi SPSS 16. Data tersebut diuji terlebih dahulu dengan uji kappa untuk mengetahui tingkat reliabilitas dari penilaian ketiga responden terhadap kedua kombinasi tersebut. Setelah kesepakatan antar ketiga responden baik maka setelah itu data dianalisa dengan uji wilcoxon untuk mengetahui perbedaan informasi diagnostik antara kedua pilihan kombinasi tersebut dan untuk informasi diagnostik manakah yang paling optimal penilaian didasarkan dengan melihat mean rank. 


\section{Hasil dan Pembahasan}

Gambar 1, menunjukkan hasil citra salah satu sampel CT Scan kepala potongan axial pada kasus stroke iskemik yang telah

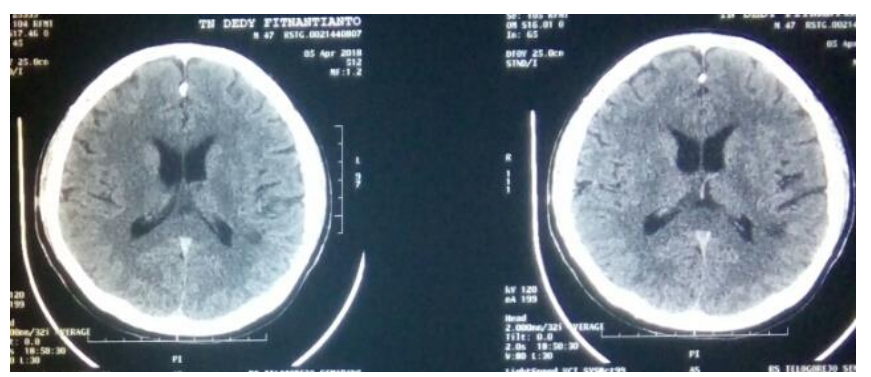

(a)

(b)

Gambar 1. Hasil citra salah satu sampel penggunaan kombinasi Slice thickness $3 \mathrm{~mm}$ dengan interval reconstruction $1.5 \mathrm{~mm}$ (a), slice thickness $2 \mathrm{~mm}$ dengan interval reconstruction $1 \mathrm{~mm}(\mathrm{~b})$

Kriteria informasi diagnostik yang dinilai meliputi tampak jelas daerah basal ganglia, tampak jelas daerah nucleus caudatus, tampak jelas thalamus dengan ukiran dan densitas yang normal, tampak jelas sistem ventrikel dan ukurannnya sesuai dengan usia pasien, batas tegas antara white matter dan grey matter, tidak tampak penyempitan atau ekspansi pada perifer sulci, ketebalan dan densitas pada fisssura sylvii tampak normal, dan mampu memperlihatkan lesi hipodens yang terdapat dalam otak (Apriantoro, 2012). Penilaian dilakukan dengan mengamati citra secara langsung pada workstation, kemudian memberikan skor pada tabel kuesioner yang telah disediakan. Hasil penilaian dari responden kemudian direkapitulasi.

Untuk mendukung hasil penelitian, dilakukan uji beda menggunakan aplikasi SPSS 16.00. Namun sebelumnya, data hasil penilaian informasi diagnostik terhadap dua kombinasi slice thickness dan interval reconstruction yang didapatkan dari ketiga responden terlebih dahulu dilakukan uji kappa. Dari hasil uji kappa yang telah dilakukan menunjukkan nilai Measure of Agreement yang tinggi pada responden satu (R1) dengan responden dua (R2) maka penelitian hanya menggunakan data dari salah satu diantara responden satu dan responden dua saja untuk uji statistik wilcoxon.

1. Hasil Uji Statistik Perbedaan Informasi Diagnostik CT Scan Kepala pada Kasus Stroke Iskemik dengan Kombinasi Slice Thickness $3 \mathrm{~mm}$ dengan Interval Reconstruction $1.5 \mathrm{~mm}$ dan Slice Thickness $2 \mathrm{~mm}$ dengan Interval Reconstruction $1 \mathrm{~mm}$

Tabel 1. Hasil uji wilcoxon perbedaan informasi diagnostik secara keseluruhan antara kedua kombinasi slice thickness dan interval reconstruction

\begin{tabular}{lc}
\hline \multicolumn{1}{c}{$\begin{array}{c}\text { Variasi Kombinasi Slice Thickness dan } \\
\text { Interval Reconstruction }\end{array}$} & P value \\
\hline Slice Thickness $3 \mathrm{~mm}$ Interval Reconstruction & \\
$1.5 \mathrm{~mm}$ & 0.001 \\
Slice Thickness $2 \mathrm{~mm}$ Interval Reconstruction & \\
$1 \mathrm{~mm}$ & \\
\hline
\end{tabular}

Hasil uji wilcoxon secara keseluruhan pada tabel 1 menunjukkan nilai signifikasi $p$ value $0.001(p<0.05)$, yang dinyatakan bahwa terdapat perbedaan bermakna pada informasi direkonstruksi dan direformat menjadi dua pilihan kombinasi yaitu slice thickness $3 \mathrm{~mm}$ dengan interval reconstruction $1.5 \mathrm{~mm}$ dan slice thickness $2 \mathrm{~mm}$ dengan interval reconstruction $1 \mathrm{~mm}$.

diagnostik kepala dengan kasus stroke iskemik antara kombinasi slice thickness $3 \mathrm{~mm}$ dengan interval reconstruction $1.5 \mathrm{~mm}$ dan slice thickness $2 \mathrm{~mm}$ dengan interval reconstruction $1 \mathrm{~mm}$.

Hasil uji dari penelitian sesuai dengan teori Nagel (2004) yang mengatakan bahwa semakin tipis slice thickness yang dipilih maka akan semakin banyak informasi diagnostik yang didapat, detail citra yang dihasilkan juga akan semakin tinggi meskipun citra cenderung akan menjadi noise.

Untuk nilai interval reconstruction menurut Priftis (2010) dengan nilai interval reconstruction $\geq 50 \%$ dari slice thickness dapat mengurangi partial volume, sehingga dapat meningkatkan densitas serta meningkatkan pengukuran volume untuk lesi yang kecil. Dengan begitu tebal tipisnya slice thickness dan interval reconstruction berpengaruh pada jumlah informasi diagnostik yang didapat.

Tabel 2. Hasil uji wilcoxon perbedaan informasi diagnostik setiap anatomi antara kedua kombinasi slice thickness dan interval reconstruction

\begin{tabular}{|c|c|c|}
\hline Kriteria & $\begin{array}{c}\text { Variasi kombinasi slice thickness } \\
\text { dan interval reconstruction }\end{array}$ & value \\
\hline $\begin{array}{l}\text { Basal } \\
\text { ganglia }\end{array}$ & $\begin{array}{l}\text { Slice thickness } 3 \mathrm{~mm} \text { Interval } \\
\text { reconstruction } 1.5 \mathrm{~mm} \\
\text { Slice thickness } 2 \mathrm{~mm} \\
\text { reconstruction } 1 \mathrm{~mm}\end{array}$ & 0.008 \\
\hline $\begin{array}{l}\text { Nucleus } \\
\text { caudatus }\end{array}$ & $\begin{array}{l}\text { Slice thickness } 3 \mathrm{~mm} \text { Interval } \\
\text { reconstruction } 1.5 \mathrm{~mm} \\
\text { Slice thickness } 2 \mathrm{~mm} \text { Interval } \\
\text { reconstruction } 1 \mathrm{~mm}\end{array}$ & 0.002 \\
\hline Thalamus & $\begin{array}{l}\text { Slice thickness } 3 \mathrm{~mm} \text { Interval } \\
\text { reconstruction } 1.5 \mathrm{~mm} \\
\text { Slice thickness } 2 \mathrm{~mm} \text { Interval } \\
\text { reconstruction } 1 \mathrm{~mm}\end{array}$ & 0.025 \\
\hline $\begin{array}{l}\text { Sistem } \\
\text { ventrikel }\end{array}$ & $\begin{array}{l}\text { Slice thickness } 3 \mathrm{~mm} \text { Interval } \\
\text { reconstruction } 1.5 \mathrm{~mm} \\
\text { Slice thickness } 2 \mathrm{~mm} \text { Interval } \\
\text { reconstruction } 1 \mathrm{~mm}\end{array}$ & 0.046 \\
\hline $\begin{array}{l}\text { White dan } \\
\text { Grey matter }\end{array}$ & $\begin{array}{l}\text { Slice thickness } 3 \mathrm{~mm} \text { Interval } \\
\text { reconstruction } 1.5 \mathrm{~mm} \\
\text { Slice thickness } 2 \mathrm{~mm} \text { Interval } \\
\text { reconstruction } 1 \mathrm{~mm}\end{array}$ & 0.005 \\
\hline Perifer sulci & $\begin{array}{l}\text { Slice thickness } 3 \mathrm{~mm} \text { Interval } \\
\text { reconstruction } 1.5 \mathrm{~mm} \\
\text { Slice thickness } 2 \mathrm{~mm} \text { Interval } \\
\text { reconstruction } 1 \mathrm{~mm}\end{array}$ & 0.317 \\
\hline $\begin{array}{l}\text { Fissura } \\
\text { sylvii }\end{array}$ & $\begin{array}{l}\text { Slice thickness } 3 \mathrm{~mm} \text { Interval } \\
\text { reconstruction } 1.5 \mathrm{~mm} \\
\text { Slice thickness } 2 \mathrm{~mm} \text { Interval } \\
\text { reconstruction } 1 \mathrm{~mm}\end{array}$ & 1.000 \\
\hline $\begin{array}{l}\text { Lesi } \\
\text { hipodens }\end{array}$ & $\begin{array}{l}\text { Slice thickness } 3 \mathrm{~mm} \text { Interval } \\
\text { reconstruction } 1.5 \mathrm{~mm} \\
\text { Slice thickness } 2 \mathrm{~mm} \text { Interval } \\
\text { reconstruction } 1 \mathrm{~mm}\end{array}$ & 0.014 \\
\hline
\end{tabular}


Hasil uji beda setiap kriteria anatomi di tabel 2 menunjukkan bahwa nilai signifikasi $p$ value untuk organ basal ganglia yaitu sebesar 0.008 , organ nucleus caudatus sebesar 0.002 , organ thalamus sebesar 0.025 , organ sistem ventrikel sebesar 0.046, organ white dan grey matter sebesar 0.005 , lesi hipodens sebesar 0.014 atau ( $p$ value < 0.05 ) yang berarti ada perbedaan informasi diagnostik pada organ basal ganglia, nucleus caudatus, thalamus, sistem ventrikel, white dan grey matter, dan lesi hipodens dari kedua pilihan kombinasi slice thickness dengan interval reconstruction. Sedangkan nilai signifikasi $p$ value untuk organ perifer sulci yaitu 0.317 dan organ fissura sylvii yaitu 1.000 atau ( $p$ value > 0.05 ) yang berarti tidak ada perbedaan informasi diagnostik pada organ perifer sulci dan fissura sylvii dari kedua pilihan kombinasi slice thickness dengan interval reconstruction.

Menurut peneliti adanya perbedaan disetiap kriteria anatomi seperti pada organ basal ganglia, nucleus caudatus, thalamus, sistem ventrikel, white dan grey matter, dan lesi hipodens dikarenakan penggunaan kombinasi slice thickness dan interval reconstruction yang lebih tipis yaitu slice thickness $2 \mathrm{~mm}$ dengan interval reconstruction $1 \mathrm{~mm}$, sehingga menampilkan kontras resolusi dan spasial resolusi citra dari masing - masing bagian organ terlihat lebih jelas terutama pada penampilan gambaran anatomisnya. Untuk organ perifer sulci dan fissura sylvii tidak memperlihatkan perbedaan antara

\begin{tabular}{lc}
\hline $\begin{array}{l}\text { Variasi kombinasi slice thickness } \\
\text { dan interval reconstruction }\end{array}$ & Mean Rank \\
\hline $\begin{array}{l}\text { Slice thickness } 3 \mathrm{~mm} \text { Interval } \\
\text { reconstruction } 1.5 \mathrm{~mm}\end{array}$ & 0.00 \\
$\begin{array}{l}\text { Slice thickness } 2 \mathrm{~mm} \text { interval } \\
\text { reconstruction } 1 \mathrm{~mm}\end{array}$ & 21.00
\end{tabular}
reconstruction $1 \mathrm{~mm}$

penggunaan kombinasi slice thickness $3 \mathrm{~mm}$ dengan interval reconstruction $1.5 \mathrm{~mm}$ dan slice thickness $2 \mathrm{~mm}$ dengan interval reconstruction $1 \mathrm{~mm}$, dikarenakan pada kedua kombinasi tersebut sudah dapat secara jelas menilai gambaran anatomis dari organ perifer sulci dan fissura sylvii.

2. Informasi diagnostik yang paling optimal antara kombinasi slice thickness $3 \mathrm{~mm}$ dengan interval reconstruction $1.5 \mathrm{~mm}$ dan slice thickness $2 \mathrm{~mm}$ dengan interval reconstruction $1 \mathrm{~mm}$

Tabel 3. Hasil Mean Rank Uji Wilcoxon pada Informasi Diagnostik Secara Keseluruhan Antara Kedua Kombinasi Slice Thickness dan Interval Reconstruction

Tabel 4. Hasil Mean Rank Uji Statistik Wilcoxon pada Informasi Diagnostik Setiap Kriteria Anatomi Antara Kedua

Kombinasi Slice Thickness dan Interval Reconstruction

\begin{tabular}{|c|c|c|}
\hline Kriteria & $\begin{array}{l}\text { Variasi kombinasi slice thickness } \\
\text { dan interval reconstruction }\end{array}$ & $\begin{array}{r}\text { Mean } \\
\text { Rank }\end{array}$ \\
\hline $\begin{array}{l}\text { Basal } \\
\text { ganglia }\end{array}$ & $\begin{array}{l}\text { Slice thickness } 3 \mathrm{~mm} \text { Interval } \\
\text { reconstruction } 1.5 \mathrm{~mm} \\
\text { Slice thickness } 2 \mathrm{~mm} \text { Interval } \\
\text { reconstruction } 1 \mathrm{~mm}\end{array}$ & 0.00 \\
\hline $\begin{array}{l}\text { Nucleus } \\
\text { caudatus }\end{array}$ & $\begin{array}{l}\text { Slice thickness } 3 \mathrm{~mm} \text { Interval } \\
\text { reconstruction } 1.5 \mathrm{~mm} \\
\text { Slice thickness } 2 \mathrm{~mm} \\
\text { reconstruction } 1 \mathrm{~mm}\end{array}$ & $\begin{array}{l}0.00 \\
5.50\end{array}$ \\
\hline Thalamus & 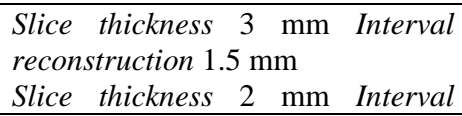 & 0.00 \\
\hline
\end{tabular}

\begin{tabular}{|c|c|c|}
\hline & reconstruction $1 \mathrm{~mm}$ & \\
\hline $\begin{array}{l}\text { Sistem } \\
\text { ventrikel }\end{array}$ & $\begin{array}{l}\text { Slice thickness } 3 \mathrm{~mm} \text { Interval } \\
\text { reconstruction } 1.5 \mathrm{~mm} \\
\text { Slice thickness } 2 \mathrm{~mm} \text { Interval } \\
\text { reconstruction } 1 \mathrm{~mm}\end{array}$ & 0.00 \\
\hline $\begin{array}{l}\text { White } \\
\text { dan Grey } \\
\text { matter }\end{array}$ & 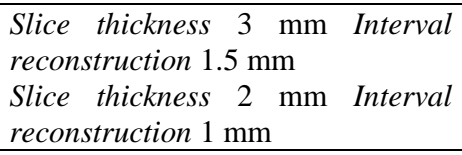 & 0.00 \\
\hline $\begin{array}{l}\text { Perifer } \\
\text { sulci }\end{array}$ & $\begin{array}{l}\text { Slice thickness } 3 \mathrm{~mm} \text { Interval } \\
\text { reconstruction } 1.5 \mathrm{~mm} \\
\text { Slice thickness } 2 \mathrm{~mm} \text { Interval } \\
\text { reconstruction } 1 \mathrm{~mm}\end{array}$ & $\begin{array}{l}0.00 \\
1.00\end{array}$ \\
\hline $\begin{array}{l}\text { Fissura } \\
\text { sylvii }\end{array}$ & $\begin{array}{l}\text { Slice thickness } 3 \mathrm{~mm} \text { Interval } \\
\text { reconstruction } 1.5 \mathrm{~mm} \\
\text { Slice thickness } 2 \mathrm{~mm} \text { Interval } \\
\text { reconstruction } 1 \mathrm{~mm}\end{array}$ & 0.00 \\
\hline $\begin{array}{l}\text { Lesi } \\
\text { hipodens }\end{array}$ & $\begin{array}{l}\text { Slice thickness } 3 \mathrm{~mm} \text { Interval } \\
\text { reconstruction } 1.5 \mathrm{~mm} \\
\text { Slice thickness } 2 \mathrm{~mm} \text { Interval } \\
\text { reconstruction } 1 \mathrm{~mm}\end{array}$ & 0.00 \\
\hline
\end{tabular}

Dari tabel 4 menunjukkan bahwa kombinasi slice thickness $2 \mathrm{~mm}$ dengan interval reconstruction $1 \mathrm{~mm}$ memiliki nilai yang lebih tinggi dibanding dengan kombinasi slice thickness $3 \mathrm{~mm}$ dengan interval reconstruction $1.5 \mathrm{~mm}$. Nilai mean rank pada pilihan kombinasi slice thickness $2 \mathrm{~mm}$ dengan interval reconstruction $1 \mathrm{~mm}$ adalah 21.00 .

Selanjutnya, berdasarkan nilai mean rank setiap kriteria anatomi menunjukkan bahwa kombinasi slice thickness $2 \mathrm{~mm}$ dengan interval reconstruction $1 \mathrm{~mm}$ memiliki nilai mean rank yang lebih tinggi yaitu pada organ basal ganglia dengan mean rank 4.00, nucleus caudatus dengan mean rank 5.50, thalamus dengan mean rank 3.00, sistem ventrikel dengan mean rank 2.50 , white dan grey matter dengan mean rank 4.50, perifer sulci dengan mean rank 1.00 dan lesi hipodens dengan mean rank 3.50, sedangkan nilai mean rank pada organ basal ganglia nucleus caudatus, thalamus, sistem ventrikel, white dan grey matter, perifer sulci dan lesi hipodens pada pilihan kombinasi slice thickness $3 \mathrm{~mm}$ dengan interval reconstruction $1.5 \mathrm{~mm}$ adalah 0.00. Hal ini disebabkan karena penggunaan slice thickness $2 \mathrm{~mm}$ dengan interval reconstruction $1 \mathrm{~mm}$ sesuai dengan karakteristik organ yang diamati. Namun, ada satu organ yang memiliki nilai mean rank yang sama antara kedua kombinasi slice thickness dengan interval reconstruction yaitu pada organ fissura sylvii dengan nilai mean rank 0.00 . Hal ini menunjukkan bahwa pada kedua kombinasi tersebut memiliki kemampuan yang sama dalam memperlihatkan organ fissura sylvii, sehingga tidak ada perubahan yang signifikan ketika slice thickness dan interval reconstruction diubah menjadi lebih tipis.

Sebelumnya Baert (2011) menyarankan penggunaan ukuran slice thickness $3 \mathrm{~mm}$ baik untuk memperlihatkan gambaran infark secara jelas. Sedangkan Hosten dan Liebeg (2002) menyarankan ukuran slice thickness $2 \mathrm{~mm}$ untuk memperlihatkan secara optimal gambaran infark. Untuk nilai interval reconstruction penelitian sebelumnya yang dilakukan oleh Wicaksono (2017) menyarankan bahwa nilai interval reconstruction yang optimal adalah adalah $50 \%$ dari nilai slice thickness yang digunakan. Namun pada penelitian ini menunjukkan slice thickness $2 \mathrm{~mm}$ dengan interval reconstruction $1 \mathrm{~mm}$ yang paling optimal karena lebih banyak dalam memberikan informasi diagnostik. 


\section{Simpulan}

Berdasarkan dari hasil uji beda wilcoxon untuk keseluruhan organ didapatkan hasil yaitu nilai $p$ value sebesar $0.001(\mathrm{p}<0.05)$ yang berarti ada perbedaan informasi diagnostik untuk keseluruhan organ pada kombinasi slice thickness $3 \mathrm{~mm}$ dengan interval reconstruction $1.5 \mathrm{~mm}$ dan kombinasi slice thickness $2 \mathrm{~mm}$ dengan interval reconstruction $1 \mathrm{~mm}$ dalam pemeriksaan CT Scan kepala pada kasus stroke iskemik. Nilai slice thickness dan interval reconstruction yang optimal untuk pemeriksaan CT Scan kepala pada kasus stroke iskemik ada pada kombinasi slice thickness $2 \mathrm{~mm}$ dengan interval reconstruction $1 \mathrm{~mm}$. Hal ini ditunjukkan dengan mean rank pada kombinasi ini sebesar 21.00.

\section{Daftar Pustaka}

Apriantoro, N.S. 2012. Analisis Variasi Nilai Window Width CT Scan Kepala Pada Kasus Stroke Non Hemoragik. Jakarta: ResearchGate

Baert, AL, 2011, "Comparative Interpretation of CT and Standard Radiography of The Chest", Springer Heidelberg Dordrecht, London.

Baert, AL, 2009, "Multislice CT”, Springer Heidelberg Dordrecht, London.

Hosten, Norbert and Thomas Liebig.2002. CT of the Head and Spine. New York: Thieme.

Kelompok Studi Serebrovaskuler \& Neurogeriatri Perdossi (KSSNP). 1999. Konsensus Nasional Pengelolaan Stroke di Indonesia. Jakarta.

Nagel, HD. 2004. Fundamental of neuroimaging. WB Saunders Company : Philadelphia, USA.

Papp, Jeffrey, PhD, RT(R)(QM), 2002, Quality Management in The Imaging Sciences, third edition. Mosby Elsevier, Inc. Missoouri.

Priftis, Kostas N, 2010, "Pediatric Bronchoscopy, Vol: 38", Karger AG, Switzerland.

Saba, Luca and Jasjit S. Suri. 2014. Multi-Detector CT Imaging. New York : CRC Press.

Wicaksono, Tri. 2017. Perbedaan Kualitas Citra CT Scan Kepala Terhadap Nilai Reconstruction Increment Pada Kasus Metastase. Semarang: repositorypoltekkessemarang 